\title{
The supportive supervisory scale: psychometric properties in Chinese health care aides samples
}

Li Tian ${ }^{1,2^{*+}}$ (0), Haixia Li2 ${ }^{2,3+}$, Bei Dong ${ }^{1,2}$, Congyan Xie ${ }^{2}$, Hong Wang ${ }^{2,3}$ and Lu Lin ${ }^{1,2^{*}}$

\begin{abstract}
Objective: To sinicize the Supportive Supervisory Scale (SSS) and analyze the psychometric properties of the Chinese version of SSS (SSS-C).

Methods: The SSS (the original English version) was firstly sinicized and adjusted, then its psychometric properties were examined in 300 health care aides from four long-term care (LTC) facilities. SPSS 22.0 was used to process the data and calculate the reliability and validity.

Results: The 15-item SSS-C had satisfactory internal consistency (Cronbach's a coefficient $=0.852$ ), split half reliability (Spearman-Brown coefficient $=0.834$ ) and test-retest reliability (Pearson correlation coefficient $=0.784$ ), and three factors were extracted. If the four items with their communality $<0.4$ were deleted, the remaining 11 items could explain $55.654 \%$ of the total variance. The discriminant validity of the SSS-C varied significantly between sites.
\end{abstract}

Conclusions: The Chinese version of SSS can be used to effectively measure the supervisory support of the nurses within the LTC settings.

Keywords: Supportive supervisory scale, Chinese version, Psychometric properties, Health care aides

\section{Introduction}

With the aging of global population, the needs for longterm care (LTC) have increased significantly. However, most of long-term care facilities (LTCFs) have been faced with the staffing challenges, resulting in poor capacity to provide competent and high-quality long-term care to the elderly [1-3]. Health care aides (HCAs, equivalent to nursing assistants) provided $80-90 \%$ of the direct care to LTCF residents [4]. Thus, it can be seen that the stability and quality of HCAs affect the nursing care of LTCFs to a considerable extent. In LTCFs, HCAs are often supervised by registered nurses, and evidence is accumulating

\footnotetext{
*Correspondence: tianlisz@suda.edu.cn; linlu@suda.edu.cn

${ }^{\dagger} \mathrm{Li}$ Tian and Haixia Li have contributed equally to this work

${ }^{1}$ The First Affiliated Hospital of Soochow University, Suzhou 215006, People's Republic of China

Full list of author information is available at the end of the article
}

that these supervisory relationships prominently affect HCA turnover, job satisfaction, and the quality of the care provided $[3,5,6]$. In addition, supportive supervisory practices have been proven to be associated with patient outcomes, for example, less adverse events and complications [7]. Therefore, it is urgent to measure and improve the supervisory support of HCA supervisors in the LTCFs.

Supportive Supervisory Scale (SSS) has been originally developed in English for this purpose and has been proven to be a reliable, valid, and useful tool to assess the supervisory support of supervisors in LTCFs, which may influence the retention of HCAs and quality of resident care [8]. To date, such instruments to evaluate the supervisory support of the supervisors within LTCFs are still lacking in China. Given the above needs, the authors obtained the authorization from the author of the original SSS scale, Prof. McGilton, and sinicized and adapted original author(s) and the source, provide a link to the Creative Commons licence, and indicate if changes were made. The images or other third party material in this article are included in the article's Creative Commons licence, unless indicated otherwise in a credit line to the material. If material is not included in the article's Creative Commons licence and your intended use is not permitted by statutory regulation or exceeds the permitted use, you will need to obtain permission directly from the copyright holder. To view a copy of this licence, visit http://creativecommons.org/licenses/by/4.0/. The Creative Commons Public Domain Dedication waiver (http://creativeco mmons.org/publicdomain/zero/1.0/) applies to the data made available in this article, unless otherwise stated in a credit line to the data. 
it, and then examined the psychometric properties of the Chinese version of SSS for use in China.

\section{Methods}

This study was approved by the Ethics Committee of Soochow University (No. SUDA 20200515H03). All participants were given both verbal and written information about the study; those who agreed to participate in this study signed an informed consent.

\section{Instrument and sinicization}

The SSS has 15 items and includes two parts. The first part is labeled "Respect Uniqueness" and the second part "Being Reliable" [9]. Answer options are "never", "seldom", "occasionally", "often", "always", which successively represent the score of " $1,2,3,4,5$ ".

The SSS was translated from English into Chinese using Brislin's translation model [10]. The steps for sinicization of SSS are shown in Fig. 1. Firstly, two bilingual researchers separately translated the original SSS into Chinese. The discrepancies between these two translations were reviewed and discussed comprehensively, and formed a single version, which was then translated back into English by another bilingual researcher. The retroversion was repeatedly compared with the original SSS scale and the Chinese expressions were adjusted accordingly. Throughout the Chinese version, "supervisor" was replaced by "nurse supervisor" to make the items more understandable since HCAs report directly to registered nurses in LTCFs in China. During this procedure, the translation validity index (TVI) was used to assess the translation equivalence of versions. It used a 4-point Likert scale $(1=$ uncorrected, $2=$ needs major modification on equivalent item, $3=$ equivalent but needs minor modification, and $4=$ equivalent). In this study, three language experts were recruited to compare the SSS in English and Chinese. The items were revised until a TVI score of 4 was achieved. The revised version of SSS was pilot tested with a convenience sample of 30 HCAs in a LTCF in Suzhou to evaluate whether the Chinese version of SSS was easy to understand. Language expression was adjusted if HCAs felt it was difficult to understand. After the pilot test, the

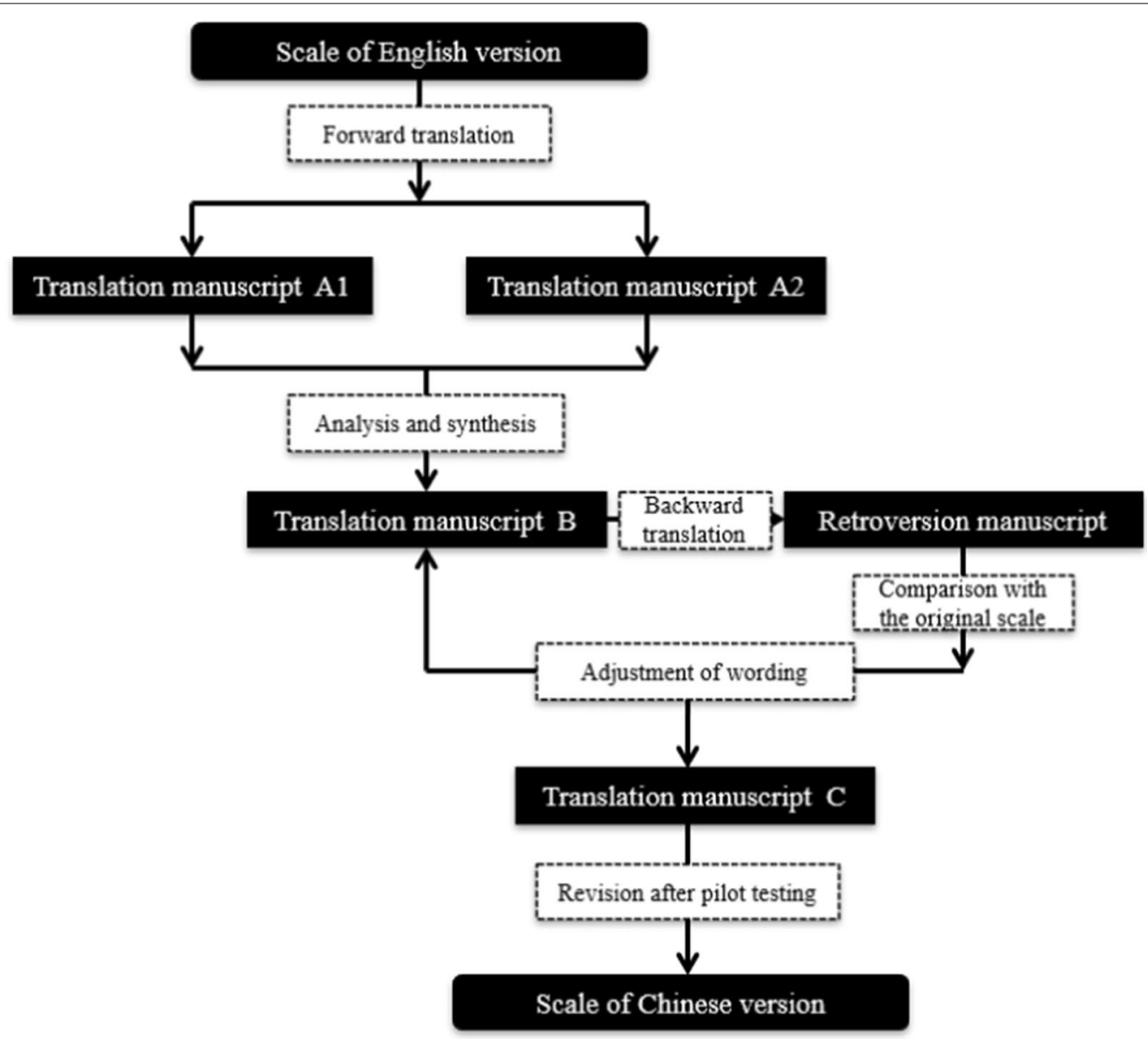

Fig.1 Sinicization steps of SSS 
Chinese version of SSS (SSS-C) was finalized for the test of its psychometric properties.

\section{Sample and setting}

The study was conducted in 4 LTCFs in Suzhou, China. Health care aides meeting the following criteria were enrolled in the study: (i) working in the LTCFs for more than 3 months; (ii) able to give written consent. A total of 300 participants completed the scale. $41.4 \%$ of the HCAs were less than 50 years old and $54 \%$ were $51-60$ years old; $85.3 \%$ were female; $100 \%$ of the respondents were employed full-time. The mean number of years that the respondents have worked in the LTCF was less than 5 years $(n=241,80.3 \%)$.

\section{Procedures}

After giving written consent, HCAs were asked to fill out the survey questionnaire independently and anonymously in the nursing station or staff lounge, without their supervisor being present. It was guaranteed that the supervisors had no access to the responses. The researchers remained in the room and were available to answer questions when necessary. Neither compensation nor remuneration was offered to the participants.

\section{Statistical analyses}

Analyses were performed by IBM SPSS Statistics 21. Participant characteristics and major variables were summarized by descriptive statistics (Table 1). Reliability was tested by internal consistency (Cronbach's alpha), split-half reliability (Spearman-Brown coefficient) and test-retest reliability (Pearson correlation coefficient) (reliability coefficient $\geq 0.7$ was acceptable) [11]. Construct validity was examined by exploratory factor analysis (EFA) (principal component analysis with varimax rotation). Scree plot, Kaiser criterion (eigenvalue $\geq 1.0$ ), and clinical interpretability were considered in determination of factor solution (When the factor loading $\geq 0.40$, the item can be considered in the factor) [12]. Discriminative validity was assessed by examining if supervisory support varied between the different facilities by one-way analysis of variance. Multiple comparisons, using Bonferroni's procedure, were completed to compare every pair of facilities. The significant level was 0.05 [13].

\section{Results}

A total of 300 HCAs were surveyed on-site and all of them completed the scale, with the response rate being $100 \%$. No data were missing and no corrections were made. Scores of the SSS-C ranged from 25 to 75 , and the mean score was $59.56(\mathrm{SD}=7.29)$ for the supervisors.

\section{Reliability}

The 15 -item SSS-C had satisfactory internal consistency (Cronbach's $\alpha$ coefficient $=0.852$ ), split half reliability (Spearman-Brown coefficient $=0.834$ ) and test-retest reliability (Pearson correlation coefficient $=0.784)$ (see Table 2). Corrected item-total correlation and Cronbach's $\alpha$ coefficient if item deleted for SSS-C are demonstrated in Table 3. The item-to-item correlations were positive, in the $0.083-0.541$ range (Table 4 ).

\section{Construct validity}

Construct validity was examined by EFA, and the Kaiser-Meyer-Olkin (KMO) measure of sampling adequacy for this analysis was satisfactory $(=0.887)$, indicating that the sample size for the EFA was adequate. The result of the Bartlett's test of sphericity was significant $\left(X^{2}=1125.922, P<0.001\right)$, demonstrating a sufficient correlation to perform factor analysis. Using the Kaiser criterion, three factors were initially identified, and total variance explained was $48.128 \%$. However, since the communality of item 1 (My supervisor recognizes my ability to deliver quality care), 4(My supervisor tries to understand my point of view when I speak to them), 5(My supervisor tries to meet my needs in such ways as informing me of what is expected of me when working with my residents) and 7(My supervisor keeps me informed of any major changes in the work environment or organization) was less than 0.4, they should be deleted in theory [14]. After deletion of these four items and a second exploratory factor analysis, three factors could still be extracted, accounting for $55.654 \%$ of the total variance $(\mathrm{KMO}=0.843$, $X^{2}=806.668, P<0.001$ ) (Table 5).

Mean item scores of the 15-item SSS ranged from 3.79 to $4.26(\mathrm{SD}=0.715$ to 1.033 ; Table 3$)$. The four items under Factor I represented 'the supervisors' need to build connections with staff that involved respecting them as individuals" [9], therefore, this factor was labeled "building connections with staff". Factor II including three items represented "the supervisors were available to staff to listen and respond to their concerns, and that they kept staff informed of what was new on the unit" [9], therefore, this factor was labeled "being dependable". Factor III was labeled "being empathic" because the items loaded on this factor represented "the supervisors try to understand their point of view, recognize and accommodate expressed needs, recognize their abilities, and help them develop" [9]. Coefficient alpha reliabilities on the items comprising the three factors were: Factor $I=0.723$, Factor $\mathrm{II}=0.588$ and Factor $\mathrm{III}=0.663$. The coefficient alpha for the 11-item SSS was 0.816 . 
Table 1 Participant characteristics $(N=300)$

\begin{tabular}{|c|c|c|c|}
\hline Socio-demographic characteristics & Number (\%) & Socio-demographic characteristics & Number (\%) \\
\hline Age & & Original occupation & \\
\hline$\leq 30$ & $3(1)$ & Relevant occupation & $104(34.7)$ \\
\hline $31-40$ & $8(2.7)$ & Unrelated occupation & $196(65.3)$ \\
\hline $41-50$ & $113(37.7)$ & How the participant obtained this job & \\
\hline $51-60$ & $162(54.0)$ & Help from relatives or friends & $159(53)$ \\
\hline$\geq 61$ & $14(4.7)$ & Help from domestic companies & $44(14.7)$ \\
\hline Gender & & $\begin{array}{l}\text { Recommended by employment center or } \\
\text { relevant departments }\end{array}$ & $20(6.7)$ \\
\hline Male & $44(14.7)$ & Official recruitment & $111(37.0)$ \\
\hline Female & $256(85.3)$ & Others & $18(6.0)$ \\
\hline Marital status & & The reasons for doing this job & \\
\hline Married (including remarriage) & $281(93.7)$ & No better work & $46(15.3)$ \\
\hline Not married (single, divorced, and widowed) & $19(6.3)$ & Stable income & $107(35.7)$ \\
\hline Education & & Want to work in the city & $23(7.7)$ \\
\hline Primary school & $111(37.0)$ & Happy to serve the elderly & $148(49.3)$ \\
\hline Junior high school & $149(49.7)$ & Learning knowledge and skills & $85(28.3)$ \\
\hline Senior high school and technical secondary school & $36(12.0)$ & Gain respect and praise & $21(7.0)$ \\
\hline$\geq$ Junior college & $4(1.3)$ & Others & $7(2.3)$ \\
\hline Residence & & Professional attitude & \\
\hline Urban & $30(10.0)$ & Respectable & $192(64.0)$ \\
\hline Town & $82(27.3)$ & No difference from other jobs & $90(30.0)$ \\
\hline Rural & $188(62.7)$ & Low social status & $18(6.0)$ \\
\hline Average monthly income & & Change profession when possible & \\
\hline$<3000 \mathrm{RMB}$ & $2(0.7)$ & Yes & $50(16.7)$ \\
\hline 3000-3999 RMB & $87(29.0)$ & No & $170(56.7)$ \\
\hline 4000-5000 RMB & $164(54.7)$ & Uncertain & $80(26.7)$ \\
\hline$>5000 \mathrm{RMB}$ & $47(15.7)$ & Type of certificate & \\
\hline Daily working hours & & No certificate & $62(20.7)$ \\
\hline$<8 \mathrm{~h}$ & $1(0.3)$ & Junior & $201(67.0)$ \\
\hline $8-9 h$ & $17(5.7)$ & Intermediate & $32(10.7)$ \\
\hline $10-12 \mathrm{~h}$ & $202(67.3)$ & Advanced & $5(1.7)$ \\
\hline$>12 \mathrm{~h}$ & $80(26.7)$ & Number of elderlies cared for & \\
\hline Years of working in this occupation & & 1 & $6(2.0)$ \\
\hline$<1$ Year & $52(17.3)$ & $2-5$ & $21(7.0)$ \\
\hline $1-3$ Years & $103(34.3)$ & $5-8$ & $222(74.0)$ \\
\hline $3-5$ Years & $86(28.7)$ & $8-10$ & $46(15.3)$ \\
\hline$>5$ Years & $59(19.7)$ & $>10$ & $5(1.7)$ \\
\hline \multicolumn{4}{|l|}{ Receive formal training } \\
\hline Yes & $282(94.0)$ & & \\
\hline No & $18(6.0)$ & & \\
\hline
\end{tabular}

*LTCF, long-term care facility

Table 2 The results of reliability analysis

\begin{tabular}{llllll}
\hline Reliability & Total (15 items) & Total (11 items) & Factor I & Factor II & Factor III \\
\hline Cronbach' a & 0.852 & 0.816 & 0.723 & 0.588 & 0.663 \\
Split-half reliability & 0.834 & 0.775 & 0.759 & 0.579 & 0.672 \\
Test-retest reliability & 0.784 & 0.740 & 0.714 & 0.660 & 0.651 \\
\hline
\end{tabular}


Table 3 Corrected item-total correlation and Cronbach's a coefficient if item deleted for SSS-C

\begin{tabular}{lllll}
\hline Item & Mean & $\begin{array}{l}\text { Standard } \\
\text { deviation }\end{array}$ & $\begin{array}{l}\text { Corrected Item- } \\
\text { total correlation }\end{array}$ & $\begin{array}{l}\text { Cronbach's a } \\
\text { if item deleted }\end{array}$ \\
\hline 1 & 4.03 & 0.715 & 0.518 & 0.842 \\
2 & 3.82 & 0.873 & 0.473 & 0.844 \\
3 & 3.79 & 1.033 & 0.394 & 0.850 \\
4 & 4.14 & 0.786 & 0.488 & 0.843 \\
5 & 3.98 & 0.782 & 0.435 & 0.845 \\
6 & 3.84 & 0.913 & 0.529 & 0.840 \\
7 & 3.92 & 0.818 & 0.408 & 0.847 \\
8 & 3.87 & 0.947 & 0.454 & 0.845 \\
9 & 4.10 & 0.729 & 0.490 & 0.843 \\
10 & 3.86 & 0.977 & 0.463 & 0.845 \\
11 & 4.15 & 0.723 & 0.525 & 0.841 \\
12 & 4.06 & 0.736 & 0.493 & 0.843 \\
13 & 4.26 & 0.821 & 0.432 & 0.846 \\
14 & 3.85 & 0.992 & 0.631 & 0.834 \\
15 & 3.87 & 0.852 & 0.587 & 0.837 \\
\hline
\end{tabular}

\section{Discriminant validity}

The discriminant validity of the SSS-C varied significantly between sites. For example, within Facility D, scores of the SSS were significantly higher than those for Facility $\mathrm{C}(F=4.791, p<0.005$; see Table 6$)$.

\section{Discussion}

This was the first study to sinicize and validate a Chinese version of the SSS. The psychometrics results supported the utility of the SSS-C. It can be used as a reliable and valid instrument to determine the supervisory support of the team leader within LTC settings. It can be used in LTCFs across China, so that cross-cultural comparisons of influencing factors for registered nurses' supportive supervision can be made possible, of which results can be popularized internationally to improve the quality of resident care. The EFA procedures carried out on the 15 -item SSS-C in the present study were performed on an adequate sample of HCAs [15], and accepted criteria were used to determine the best factor solution. After consultation with experts on long-term care, it has been suggested that these four items need to be further modified in future research due to poor communality or new items could be added for a more complete measure of supervisory support in the Chinese context.

The results of the three-factor rotated solution were compatible with the three dimensions upon which the original SSS was initially based [9], however, they were discrepant with the original SSS which only has two dimensions. The three factors (building connections with staff, being dependable, and being empathic) were consistent with the theoretical underpinning of the SSS. At the core of effective supervision is a supervisor's ability to develop and maintain positive working relationships with each HCA (what the dimension "building connections with staff" represents) [8], which can enhance the connection, cooperation and team work among the nurse supervisors and HCAs, and may significantly influence the HCA turnover and patient outcomes [16, 17]. Supportive supervision was defined as the extent to which the leader demonstrated empathy and reliability (also referred to as dependability) with staff [8]. The other two dimensions "being dependable" and "being empathic" were consistent with the above concepts. When HCAs

Table 4 Item-to-item correlations for 15 -item SSS-C

\begin{tabular}{|c|c|c|c|c|c|c|c|c|c|c|c|c|c|c|c|}
\hline Item & 1 & 2 & 3 & 4 & 5 & 6 & 7 & 8 & 9 & 10 & 11 & 12 & 13 & 14 & 15 \\
\hline 1 & 1.000 & & & & & & & & & & & & & & \\
\hline 2 & .357 & 1.000 & & & & & & & & & & & & & \\
\hline 3 & .230 & .267 & 1.000 & & & & & & & & & & & & \\
\hline 4 & .314 & .330 & .267 & 1.000 & & & & & & & & & & & \\
\hline 5 & .228 & .334 & .174 & .276 & 1.000 & & & & & & & & & & \\
\hline 6 & .310 & .325 & .337 & .312 & .245 & 1.000 & & & & & & & & & \\
\hline 7 & .250 & .196 & .186 & .257 & .207 & .296 & 1.000 & & & & & & & & \\
\hline 8 & .253 & .183 & .130 & .223 & .209 & .308 & .254 & 1.000 & & & & & & & \\
\hline 9 & .232 & .238 & .174 & .232 & .290 & .336 & .288 & .353 & 1.000 & & & & & & \\
\hline 10 & .293 & .136 & .263 & .287 & .277 & .305 & .242 & .346 & .287 & 1.000 & & & & & \\
\hline 11 & .315 & .392 & .203 & .280 & .277 & .276 & .190 & .239 & .365 & .271 & 1.000 & & & & \\
\hline 12 & .372 & .231 & .140 & .291 & .240 & .235 & .231 & .276 & .269 & .287 & .447 & 1.000 & & & \\
\hline 13 & .272 & .298 & .083 & .268 & .267 & .200 & .121 & .190 & .241 & .140 & .345 & .321 & 1.000 & & \\
\hline 14 & .384 & .286 & .342 & .345 & .277 & .361 & .278 & .371 & .275 & .334 & .349 & .389 & .541 & 1.000 & \\
\hline 15 & .363 & .312 & .377 & .257 & .253 & .378 & .331 & .348 & .392 & .276 & .330 & .306 & .267 & .472 & 1.000 \\
\hline
\end{tabular}


Table 5 Results of exploratory factor analysis

\begin{tabular}{|c|c|c|c|c|}
\hline \multirow[t]{2}{*}{ Items } & \multirow[t]{2}{*}{ Communality } & \multicolumn{3}{|l|}{ Factors } \\
\hline & & Factor 1 & Factor 2 & Factor 3 \\
\hline 13. My supervisor respects me as a person & 0.623 & 0.789 & & \\
\hline 11. My supervisor encourages me even in difficult situations & 0.488 & 0.644 & & \\
\hline 12. My supervisor makes a point of expressing appreciation when I do a good job & 0.502 & 0.619 & & \\
\hline 14. My supervisor makes time to listen to me & 0.525 & 0.565 & & \\
\hline 1.My supervisor recognizes my ability to deliver quality care & 0.387 & 0.451 & & \\
\hline $\begin{array}{l}\text { 5.My supervisor tries to meet my needs in such ways as informing me of what is expected of me } \\
\text { when working with my residents }\end{array}$ & 0.284 & 0.417 & & \\
\hline 8. I can rely on my supervisor to be open to any remarks I may make to him/her & 0.567 & & 0.726 & \\
\hline 10. My supervisor strikes a balance between clients/ families' concerns and mine & 0.444 & & 0.622 & \\
\hline 9. My supervisor keeps me informed of any decisions that were made in regards to my residents & 0.451 & & 0.603 & \\
\hline 7.My supervisor keeps me informed of any major changes in the work environment or organization & 0.376 & & 0.542 & \\
\hline 15. My supervisor recognizes my strengths and areas for development & 0.487 & & 0.469 & \\
\hline 3. My supervisor knows me well enough to know when I have concerns about resident care & 0.655 & & & 0.797 \\
\hline 2. My supervisor tries to meet my needs & 0.565 & & & 0.553 \\
\hline $\begin{array}{l}\text { 6. I can rely on my supervisor when I ask for help, for example, if things are not going well between } \\
\text { myself and my co-workers or between myself and residents and/or their families }\end{array}$ & 0.488 & & & 0.542 \\
\hline 4.My supervisor tries to understand my point of view when I speak to them & 0.378 & & & 0.458 \\
\hline
\end{tabular}

Table 6 Divergent construct validity across the long-term care facilities

\begin{tabular}{llllll}
\hline Facility & Type of LTCF & Number of beds & Number of HCAs & Number of supervisors & $\begin{array}{l}\text { Supportive } \\
\text { supervisory scores } \\
\text { (mean } \pm \text { SD) }\end{array}$ \\
\hline A & & & & $58.71 \pm 5.61$ \\
B & Private & 582 & 80 & 42 & $60.42 \pm 5.54$ \\
C & Private & 230 & 24 & 7 & $57.22 \pm 8.19$ \\
D & Public & 600 & 65 & 52 & $61.08 \pm 7.69$ \\
Total & Public & 664 & 131 & 124 & $59.56 \pm 7.29$ \\
ANOVA & & 2076 & 300 & & $F=4.791$ \\
{$[P$ value $]$} & & & & {$[0.003]$}
\end{tabular}

LTCF, long-term care facility; HCA, health care aides

can depend on their supervisors to achieve, relate to and enjoy their work, it will be easier for them to be committed to their work and become devoted caregivers [18]. Nurse supervisors in the LTCFs can help the staff counteract the negative effects of work-related pressure, perform their best over the long-term using Mindfulness, Hope and Compassion [19]. Therefore, "being dependable" and "being empathic" were also very important qualities of the supervisors in the LTCFs.

The discriminant validity of the SSS-C was also examined relative to construct validity, which showed that the SSS-C was able to differentiate supportive behaviors of supervisors between different LTCFs. No concurrent measure was conducted because there were no appropriate instruments.
The study has a few limitations. First, this study used a convenience sample of HCAs from the LTCFs in Suzhou. Second, no concurrent measure was conducted to analyze the construct validity. Third, in future research, new items could be added through expert consultation to form a more comprehensive measure of supervisory support in the Chinese context.

\section{Conclusions}

The reliability and validity of the Chinese version of the SSS were acceptable. A strong three-factor solution was obtained, which was consistent with the three dimensions upon which the original SSS was initially based. At the core of supportive supervision is the supervisor's ability to develop and maintain relationships with the 
HCAs. Through their dependability and empathy, these relationships can prosper. The SSS-C can be used as a reliable and valid tool to measure the level of supportive supervision in the LTCFs, which may influence retention of HCAs and quality of resident care.

\section{Acknowledgements}

We would like to express our heartfelt gratitude to the data collectors and study participants. This study would not have been possible without their contributions.

\section{Authors' contributions}

Tian L, Lin L, and Li HX translated the scale and performed the cultural adaption. $\mathrm{Li} H X$, Dong $B$, Xie CY, and Wang H performed the survey. Tian L, and Lin $L$ wrote the first draft of the manuscript. Tian $L$ revised the final manuscript. All authors read and approved the final manuscript.

\section{Funding}

This study was funded by the Humanity and Social Science Youth Foundation of Ministry of Education of China (Project No. 18YJCZH164) and National Natural Science Foundation of China (Grant No. 81801098).

\section{Availability of data and materials}

The authors have full control of all primary data and agree to allow the journal to review the data if requested.

\section{Ethics approval and consent to participate}

This study acquired ethical approval from the Medical Ethics Committee of Soochow University (No. SUDA 20200515H03). All participants signed the informed consent form.

\section{Consent for publication}

All participants have read the final manuscript and agreed to publish the data included in this manuscript.

\section{Competing interests}

The authors have no conflicts of interest to disclose.

\section{Author details}

${ }^{1}$ The First Affiliated Hospital of Soochow University, Suzhou 215006, People's Republic of China. ${ }^{2}$ School of Nursing, Medical College of Soochow University, No. 1 Shizi Street, 215006 Suzhou, People's Republic of China. ${ }^{3}$ Suzhou Jiulong Hospital, Shanghai Jiao Tong University School of Medicine, Suzhou, People's Republic of China.

Received: 4 August 2020 Accepted: 15 February 2021

Published online: 23 February 2021

\section{References}

1. Castle NG, Kathryn $\mathrm{H}$, Harris JA, et al. Nurse aide retention in nursing homes. Gerontologist. 2020. https://doi.org/10.1093/geront/gnz168.
2. Escrig-Pinol A, Corazzini KN, Blodgett MB, et al. Supervisory relationships in long-term care facilities: a comparative case study of two facilities using complexity science. J Nurs Manag. 2019;27(2):311-9.

3. Mcgilton KS, Bowers BJ, Heath $\mathrm{H}$, et al. Recommendations from the international consortium on professional nursing practice in long-term care homes. J Am Med Direct Assoc. 2015;17(2):99-103.

4. Caspar, S. The influence of information exchange processes on the provision of person-centred care in residential care facilities (Doctoral thesis). University of British Columbia, Vancouver, Canada, 2014.

5. Ericson-Lidman E, Larsson LLF, Norberg A. Caring for people with dementia disease (DD) and working in a private not-for-profit residential care facility for people with DD. Scand J Caring Sci. 2014;28(2):337-46.

6. Mcgilton $\mathrm{KS}$, Chu CH, Shaw AC, et al. Outcomes related to effective nurse supervision in long-term care homes: an integrative review. J Nurs Manag. 2016;24(8):1007-26.

7. Wong CA, Cummings GG. The relationship between nursing leadership and patient outcomes: a systematic review. J Nurs Manag. 2007:15:508-21.

8. Le Anne SC, McGilton KS. The influence of supportive supervisory practices and health care aides'self-determination on the provision of person-centered care in long-term care facilities. J Appl Gerontol. 2019;38(11):1564-82.

9. McGilton KS. Development and psychometric testing of the supportive supervisory scale (SSS). J Nurs Scholarsh. 2010;42(2):223-32.

10. Brislin RW. The Wording and Translation of Research Instruments, vol. 8. Thousand Oaks, CA: Sage Publications, Inc; 1986.

11. Xiaolin, Z. Investigation and research on the knowledge needs of Institutional aged care workers based on post competency. Guangxi University of traditional Chinese medicine, 2019

12. Liqin, C. Development and psychometric properties of quality of life scale for residents in long-term care facilities. Shandong University, 2016

13. Lina, G. Chinesization, Evaluation and Validation of the Self-care Ability Scale for the Elderly. Jinzhou Medical University, 2016

14. Xiao-yan WU, Hong ZENG, Shao-bin MA, et al. Development of learned helplessness scale and its relationship with personality. J Sun Zhongshan Univ (Med Sci). 2009;30(03):357-61.

15. Norman G, Streiner D. Biostatistics: The bare essentials. Toronto: Mosby; 2014.

16. Anderson RA, Corazzini KN, McDaniel R Jr. Complexity science and the dynamics of climate and communication: reducing nursing home turnover. Gerontologist. 2004;44(3):378-88.

17. Anderson RA, Ammarell N, Bailey DE, et al. The power of relationship for high-quality long-term care. J Nurs Care Qual. 2005;20(2):103-6.

18. Tellis-Nayak V. A person-centered workplace: the foundation for person-centered caregiving in long-term care. J Am Med Direct Assoc. 2007:8(1):46-54.

19. McKee A, Massimilian D. Resonant leadership: a new kind of leadership for the digital age. J Bus Strat. 2006;27(5):45-9.

\section{Publisher's Note}

Springer Nature remains neutral with regard to jurisdictional claims in published maps and institutional affiliations.

Ready to submit your research? Choose BMC and benefit from

- fast, convenient online submission

- thorough peer review by experienced researchers in your field

- rapid publication on acceptance

- support for research data, including large and complex data types

- gold Open Access which fosters wider collaboration and increased citations

- maximum visibility for your research: over 100M website views per year

At BMC, research is always in progress.

Learn more biomedcentral.com/submissions 